\title{
MÁRIO DE ANDRADE: AS ENFIBRATURAS DO MODERNISMO
}

\author{
POR \\ BENEDITO NUNES \\ Universidade do Pará
}

Sessenta anos separam-nos da Semana de Arte Moderna, ocorrida em fevereiro de 1922, no Teatro Municipal de São Paulo, sob o patrocínio de figuras de proa da sociedade paulista, e que reuniu o grupo criador de jovens artistas e poetas, sob cuja ação efectivou-se, em estilo revolucionário, o processo de mudança de gosto estético, que chamamos de modernismo, catalizado pela renovação da poesia e da prosa, e que proporcionou a conquista de uma consciência cultural, decisiva e historicamente determinante, ainda nos dias de hoje, para a inteligência brasileira. $\mathrm{Na}$ verdade apenas um tríduo litero-musical —as noites de 13,15 e 17 de fevereiro daquele ano, preenchidas com exposições de arte nos saguões do teatro, e com alocuções e leituras dirigidas a uma plateia arredia, do alto de um palco italiano frequentado pelos astros estrangeiros do Canto Lírico- a Semana era a manifestação pública e festiva do nosso modernismo, que foi «uma ruptura (...) um abandono de princípios e técnicas consequentes, (...) uma revolta contra o que era a inteligência nacional» ${ }^{1}$, como diria, já em 1942, num retrospecto histórico e autobiográfico do movimento, de que teve um dos postos de liderança, o escritor Mário de Andrade.

A obra de Mário de Andrade seria, desde o começo, marcada por essa ruptura, consequente à rejeição modernista tanto da estética parnasianonaturalista, estabilizada academicamente entre nós, quanto de toda uma forma de comportamento social, decoroso e acomodatício, da nossa intelectualidade.

1 Mário de Andrade, «O Movimento Modernista», em Aspectos da Literatura Brasileira (São Paulo: Martins Editora, s/data), p. 235. 
Dificil é classificar a personalidade artística desse poeta, narrador, crítico e ensaísta, que criou, com a argúcia paciente de um pesquisador, e que pesquisou a realidade brasileira com o ímpeto luminoso de um criador. Terá sido ele o nosso primeiro scholar, surgido antes das Universidades - um singular scholar autodidata, oposto ao diletantismo-. Enquanto os seus companheiros de geração vinham, na grande maioria, das Faculdades de Direito, Mário de Andrade tinha, como título de estudos superiores, um curso de piano no Conservatório de São Paulo, que The deu a inusitada condição, àquela época, de musicólogo, avis rara entre bachareis de arribação em Letras Jurídicas. A esse poeta, que assinou ensaios capitais sobre música brasileira, e lançou os fundamentos de nossa historiografia artística -a esse musicólogo, inseparável do poeta, deve-se a poesia matricial do modernismo. Refiro-me a Paulicéia Desvairada, publicado após a Semana de Arte Moderna, ainda em 22, e em que, pela primeira vez, frutificou, e até com certo atraso, em nossas letras e artes, «o estado de espírito universal, cujas manifestações mais clamorosas, cubismo e futurismo, deram seus primeiros vagidos europeus por $1909{ }^{2}$.

Conta-nos Mário de Andrade a origem explosiva desse livro inseminador, depois da leitura de alguns poetas futuristas e do belga Emile Verhaeren (Villes Tentaculaires) em 1920. «Fora o deslumbramento. Levado em principal pelas Villes Tentaculaires, concebi imediatamente fazer um livro de poesia moderna, em verso livre, sobre a minha cidade. Tentei, não veio nada que me interessasse. Tentei mais, nada. Os meses passavam numa angústia, numa insuficiência feroz.» Foram vãs as tentativas até 1921, quando o poeta escreveu contra os ídolos da poesia parnasiana - um Raimundo Correia, um Bilac, uma Francisca Julia, um Alberto de Oliveira, um Vicente de Carvalho- a série de artigos publicados no "Jornal do Comércio» sob o título de Mestres do Passado. "O estouro chegara afinal depois de quase um ano de angústias interrogativas. Entre desgostos, trabalhos urgentes, dívidas, brigas, em pouco mais de uma semana, estava jogado no papel um canto bárbaro duas vezes maior talvez do que isso que o trabalho de arte deu num livros ${ }^{3}$. O trabalho de arte produziria 23 poemas, o último dos quais As Enfibraturas do Ipiranga; ao conjunto Mário de Andrade acrescentou um Prefácio Interessantíssimo —na verdade prefácio teórico à poesia modernista, como introdução ao novo lirismo, por ele denominado desvairista.

2 Mário de Andrade, «Modernismo», em O Empalhador de Passarinhos (São Paulo: Martins Editora, s/data), pp. 159-160.

${ }^{3}$ Mário de Andrade, "O Movimento Modernista», em Aspectos da Literatura Brasileira, cit., pp. 233-234. 
Paulicéia Desvairada ${ }^{4}$ é uma viagem lírica no espaço tenso e contraditório de São Paulo em via de transformar-se na grande cidade industrial sul-americana, onde o novo começa a sobrepujar o velho, onde gentes de várias nacionalidades misturam os seus falares, tal como se misturariam, nos poemas, a história pessoal do poeta e a memória histórica do Tietê, o rio dos bandeirantes de há dois séculos atras, que agora acompanhava largas avenidas asfaltadas, trilhos de elétricos (bondes) trepidantes e automóveis pagos com os lucros do café, enquanto em meio a um passado provinciano, de missas na Igreja de Sta. Cecília, de passeios nos parques, a antiga classe senhorial dos fazendeiros paulistas metamorfoseia-se, abandonando os seus antigos hábitos, em burguesia financiera:

São Paulo! comoção de minha vida...

Galicismo a berrar nos desertos da América!

(«Inspiração»)'

Alturas da Avenida. Bonde 3.

Asfaltos. Vastos, altos repuxos de poeira

sob o arlequinal do céu oiro-rosa-verde...

( O Domador»)

Numa cidade berrante, multicolorida como a veste de Arlequim, são contraditórios os sentimentos do cantor, que também se identifica com esse personagem da Commedia dell'Arte. $\mathrm{O}$ desvario do cantor riposta ao desvario da cidade por meio de imagens expressionistas, que estabelecem um circuito de aderência afetiva, o Eu pessoal fundido ao espaço urbano multicêntrico e pulsante:

Gingam os bondes como um fogo de artifício, sapateando nos trilhos,

cuspindo um orifício na treva cor de cal...

Um mulato cor de oiro,

com uma cabeleira feita de alianças polidas...

Violão! «Quando eu morrer...» Um cheiro pesado de baunilhas oscila, tomba e rola no chão...

(«Nocturno»)

${ }^{4}$ «Paulicéia Desvairada», em Poesias completas. Obras completas de Mário de Andrade (São Paulo: Martins Editora, 1966), pp. 9-64. 
O espaço urbano é o domínio estético do novo lirismo libertário - ou de libertação, como o denominaria Manuel Bandeira - feito de substantivos soltos, de verbos substantivados, de vocábulos livres, mobilizados pelo seu poder "associativo, simbólico, universal, musical.... ${ }^{5}$ :

Escuridão dum meio-dia de invernia... Marasmos... Estremeções... Brancos...

(«Paisagem 2»)

Arroubos... Lutas... Setas... Cantigas... Povoar!... Ritmos de Brecheret!... ${ }^{6} \mathrm{E}$ a santificação da morte! Foram-se os ouros!... E o hoje das turmalinas!...

\section{(«Tietê»)}

Primeira vitória da liberdade de expressão individual contra o passadismo, esse poema bárbaro trouxe a "vitória do dicionário», expressão pitoresca com que Mário de Andrade rebatizou o regime das «palavras em liberdade» do futurismo, principal conduto, juntamente com a justaposição característica do cubismo literário de Apollinaire, do impulso lírico, como matéria prima que o trabalho de arte converteria na forma poética, preservado o «exagero colorido» da expressão. «Exagero: simbolo sempre novo da vida como do sonho. Por ele vida e sonho se irmanam ${ }^{7}$. Correspondendo à tônica do humor, ora irreverente ora agressivo, o exagero lírico torna-se visínho da "sublime loucura» ${ }^{8}$. E o poeta desvairista sabe-se, de antemão, à margem da cidade alucinada, onde só pode introduzir-se disfarçado de Arlequim, objeto da mesma condescendência dispensada aos palhaços e aos loucos:

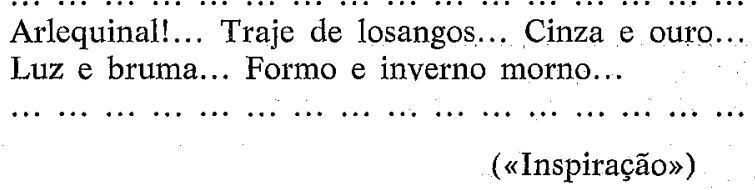

\footnotetext{
${ }^{5}$ «Paulicéia Desvairada», em Prefácio Interessantissimo. Obras completas de Mário de Andrade (São Paulo: Martins Editora, 1966), p. 22.

- Victor Brecheret, escultor paulista da época do modernismo.

7 "Paulicéia Desvairada», em Prefácio..., cit., p. 18.

${ }^{8}$ «Paulicéia Desvairada», em Prefácio..., cit., p. 26.
} 
As primaveras do sarcasmo

intermitentemente no meu coração arlequinal...

(«O Trovador»)

Arlequinal é o adjetivo desse estado de marginalização declarado do poeta, que diz de si mesmo:

Sou um tupi tangendo um alaúde!

(«O Trovador»)

Essa imagem chocante, à beira da auto-irrisão dadaísta, do primitivo brasileiro dedilhando um alaúde, o venerável instrumento, que foi, ao lado da harpa e da lira, o símbolo da cultura musical européia, assinala a presença do musicólogo em Paulicéia Desvairada. A teoria musical inspirou ao scholar Mário de Andrade a teoria poética do harmonismo ou do polifonismo, como síntese das técnicas do verso livre, difundidas pelas vanguardas do primeiro quarto de século, futurismo, cubismo e dadaísmo. $O$ verso tradicional é comparável à melodia; o verso moderno possui estrutura análoga à da polifonia, «união artística simultanea de duas ou mais melodias, cujos efeitos passageiros de embates de sons concorrem para um efeito total final» ${ }^{9}$. As «palavras em liberdade», que não se ligam entre si mediante concatenação lógico-sintática, funcionam como distintas melodias harmonizadas, produzindo o efeito único, imediato, da superposição ou associação de ideias.

Muito significativamente, o último dos artigos da série Mestres do Passado, de nosso Arlequim musicólogo, intitulou-se Prelúdio, Coral e Fuga. Nele Mário atacava os críticos passadistas, «ignaros, perversos, cães de guarda raivosos», glorificadores dos poetas parnasianos e que o tomaram como o «futurista ridículo, o burlão, o almofadinha frequentador de chás das cinco, pernósticos e desavergonhado... ${ }^{10}$. Ato de imolação de antiga paternidade intelectual, o sacrifício quase mítico dos ídolos, consumado nesse escrito, alteia-se, no Coral, num grito de desafio e de mal-

${ }^{9}$ Exposta pela primeira vez no Prefácio Interessantíssimo, firma-se em conexão com a ideia de simultaneidade, como Polifonia Poética no ensaio «A Escrava que não é Isaura» (discurso sobre algumas tendências da poesia modernista), em Obra Imatura (São Paulo: Livraria Martins Editora, 1960), pp. 195-300.

${ }_{10}$ «Mestres do Passado», em Mário da Silva Brito, História do Modernismo Brasileiro, I (Rio de Janeiro: Ed. Civilização Brasileira, 1964, 2.a ed.), p. 306. 
dição burlesca («Malditos para sempre os Mestres do Passado!»), que era também brado de confiança na rebeldia estética da mocidade: «Sobre as cascatas há de perpetuamente valsar os raios do sol, o requebro donairoso dos arco iris. E sobre os campos como nas clareiras as borboletas esvoaçarão, avançando, ferindo-se, debatendo-se, iluminando, colorindo, despetalando, queimando-se, porque as borboletas não param, as mocidades não esperam, oh! seus raimundo de correia»... «Viva o riso, a alegria, a 'blague'!", prorrompem os acordes verbais derradeiros da Fuga ${ }^{11}$. Cornparando-se a "novo Anfião moreno e caixa-d'octulos» ${ }^{12}$, exposto às vaias dos espectadores durante a Semana, o crítico-poeta também usaria da vaia, que rebenta, insultuosa, na Ode ao Burguês:

Eu insulto o burguês! O burguês-níquel, o burgtiês-burguês!

A digestão bem feita de São Paulo!

O homem-curva! o homem-nádegas!

O homem que sendo francês, brasileiro, italiano, é sempre um cauteloso pouco-a-pouco!

$\begin{array}{lllllllllllll}\ldots & \ldots & \ldots & \ldots & \ldots & \ldots & \ldots & \ldots & \ldots & \ldots & \ldots & \ldots & \ldots\end{array}$

Come! Come-te a ti mesmo, oh! gelatina pasma!

Oh! purée de batatas morais!

Fora! Fú! Fora o bom burguês!...

Não é porém o burguês, como membro da classe dominante, que essa Ode hostiliza. A irritação, menos que repulsa, do verso libertário de Mário de Andrade, dirige-se à burguesia enquanto negação do espírito, contra a vida medíocre, o embotamento artístico, a estreiteza moral e mental. Censurando-lhe o arrivismo, a pseudo cultura, o falso tradicionalismo e a falta de religiosidade autêntica, o poeta arlequinal, dissidente dos hábitos da camada intelectual a que pertencia, achou-se igualmente em desacordo com a sua própria classe, mas sem dela divergir politicamente, muito embora rejeitasse o aparato da vida política, relegada à categoria do grotesco, como no poema $O$ Rebanho, sátira aos legisladores, que desfilam transformados em cabras. "A extrema-esquerda em que nos colocamos não permite meio-termo», dizia Mário em seu Prefácio Interessantíssimo. Mas a extrema-esquerda é aí a denominação da marginalidade social agres-

${ }^{11}$ Raimundo de correia, referência ao poeta parnasiano Raimundo Correia (18591911). «Mestres do Passado», em Mário da Silva Brito, História..., cit., p. 309.

${ }_{12}$ «Paulicéia Desvairada», em Prefácio..., cit., p. 30. 
siva do poeta - reflexo da ruptura estética do modernismo- que se confunde com a sensibilidade exaltada, com a alta voltagem emocional dos versos desvairistas destinados a almas irmãs, aos poucos que soubessem cantar, urrar e chorar ${ }^{13}$.

Quem eram essas almas irmãs? Em primeiro lugar, as juvenís de seus companheiros de geração, e depois as sensibilidades refinadas da classe senhorial decadente da antiga "aristocracia rural», de cujos mais conspícuos representantes saiu o apoio oficioso à Semana de Arte Moderna -os Prado, os Penteado, os Amaral, que abririam seus salōes para as ferventes tertúlias da fase de alastramento da arte nova, durante os «banquet years» que antecederam à reviravolta política da revolução de 1930 e que cessariam com ela.

O estarrecimento social, que ainda não é crítica da sociedade, e que acompanha, em Paulicéia Desvairada, a consciência de ruptura estética com a literatura tradicional e com o modo de pensamento correlato, exprime-se, dramaticamente, no extraordinário poema de encerramento desse livro, As Enfibraturas de Ipiranga (Oratório profano), em que domina, até pela estrutura polifônica vocal e instrumental de sua composição, a poética marioandradina «desvairista» da fase combativa do modernismo. A confrontação grupal que esse conjunto orquestal-operístico nos oferece, e que examinaremos a seguir, demarcou o espaço ideológico, condicionado ao espaço urbano da cidade industrializada, dentro do qual o movimento modernista se desenvolveu.

Como está a indicar o topônimo Ipiranga, riacho à margem do qual D. Pedro proclamou o fim da subordinação política a Portugal, o título, As Enfibraturas do Ipiranga, superpõe, irônicamente, conotando o arcabouço das forças nacionais, as duas efemérides -a Independência política, cujo centenário comemorou-se em 1922, e a Independência artisticoliterária alcançada nesse memo ano. São quatro os conjuntos vocais que representam, nesse oratório profano, o confronto da Semana de Arte Moderna: Os Orientalismos Convencionais, formando «Largo, imponente coro afinadíssimo de sopranos, contraltos, baritonos, baixos»; As Senectudes Tremulinas, milionários e burgueses, integrando um coro de sopranistas; Os Sandapilários Indiferentes, barítonos e baixos, como representantes do operariado e da pobreza; e as Juvenilidades Auriverdes, tenores, secundados por uma solista, soprano ligeiro, Minha Loucura. Os passadistas, tanto escritores quanto «artífices elogiáveis», formam a coorte dos Orientalismos Convencionais, o termo Orientalismo aqui invocando o que

${ }^{13}$ «Paulicéia Desvairada», em Prefácio..., cit., p. 31. 
há de estático e mesmo de hierático no cultivo, independentemente da idade, da arte e da literatura tradicionais, apreciadas pelos milionários e burgueses -As Senectudes Tremulinas, cuja total velhice de espírito, indicada pelo arcaismo senectude, justifica o trêmulo da voz (tremulina). O substantivo sandeu, mais o verbo pilar (moer), com o sufixo ario, deu o pejorativo Sandapilário (aqueles que moem ou remoem tolices). Importa considerar, além da denominação e da composição dos conjuntos vocais, as localizações que ocupam no espaço onde evoluem, a esplanada do Teatro Municipal.

Os Orientalismos Convencionais «estão nas janelas e terraços do Teatro Municipal». As Senectudes Tremulinas ocupam as «sacadas do Automóvel Clube», ao qual perteneciam os patronos da Semana de Arte Moderna, e de outros prédios, a Prefeitura, a Rotisserie, a Tipografia Weisflog, o Hotel Carlton e a Livraria Alves, frequentados pela burguesia e pela intelectualidade. Os dois grupos ocupam os lugares mais elevados, localizando-se, portanto, no topo da sociedade. O primeiro aglutina as forças do conservadorismo acadêmico, a serviço da ordem artística, caracterizada por valores estáveis, e inseparável da ordem social: a metrificação para a poesia, o ornamental para as demais artes, a polícia da lingua através do culto da gramática, o prestígio das instituições literárias impondo a disciplina do decoro verbal, o apego às convenções e a rejeição do progresso. Os Orientalismos Convencionais, solidários às Senectudes, de que são intérpretes e defensores, desfrutam de prestígio social semelhante ao dos mandarins (o que também justifica o apelativo orientalista que recebe). A conduta deles contrasta com o ímpeto rebelde das Juvenilidades Auriverdes, dispostas à luta e ao sacrifício, e que se localizam em baixo, «nos parques do Anhangabaú, com os pés enterrados no solo»:

Nós somos as Juvenilidades Auriverdes!

As franjadas flâmulas das bananeiras, as esmeraldas das araras,

os rubis dos colibris, os lirismos dos sabiás e das jandaias, os abacaxis, as mangas, os cajús almejam localizar-se triunfantemente, na fremente celebração do Universal!...

Esse vocabulário colorístico e paisagístico está de acordo com o adjetivo auriverde atribuido às Juvenilidades, que une as cores básicas da bandeira brasileira, verde e amarelo, à afirmação nacionalista, como signo ideológico da identidade grupal do modernismo no início do movimento 
de renovação. Os Sandapilários, de cujo papel trataremos no final, «berram do Viaduto do Chá», ainda em posição eminente, acima das Juvenilidades, entre as quais evolui Minha Loucura, presença pessoal do poeta e súmula do desvario de Paulicéia:

Vá de rumor! Vá de rumor!

Esta gente não nos deixa mais dormir!

Antes «E lucevan le stelle» de Puccini! ${ }^{14}$

Oh! pé de anjo, pé de anjo!

Fóra! Fóra o que é de despertar!

Segue-se a reação pesada dos contrabaixos em crescendo, antes do canto inicial dos mandarins:

Somos os Orientalismos Convencionais!

Os alicerces não devem cair mais!

Nada de subidas ou de verticais!

Amamos as chatezas horisontais!

E um canto em fábordão, contraponto simples, nota contra nọta, sugerida pelas rimas iguais, sucessivamente em ais, $u$ s e $o$ aberto:

Só é nobre o passo dos jabirús! ${ }^{15}$.

Há estilos consagrados para Pecaembús! ${ }^{16}$.

Não the bastam velas? Para que mais luz!

Per omnia saecula saeculorum moinhos terão mó!

Antualmente de sobrecasaca, não de paletó, vamos visitas o esqueleto de nossa grande Avó!

Incerta, indireta e irreflexiva, a réplica das Juvenilidades é mais autoencorajamento do que apóstrofe aos grupos adversos:

-Pão de Icaros sobre a toalha extática do azul!

Os tuins esperanças das nossas ilusões!

Suaviloquências entre as deliquescências

dos sáfaros, aos raios do maior solar!...

\footnotetext{
${ }^{14}$ Puccini, Tosca, Ato III.

${ }^{15}$ Jabirú: o mesmo que Gaburu ou Tuiuiú, ave ciconiforme da familia dos ciconídeos (Jabiru mycteria).

${ }^{16}$ Referência a Pacaembu, novo bairro residencial à época.
} 
Os tuins, periquitos verdes, simbolizam a expectativa confiante no futuro salvador, interceptada pelo antigo compasso de minueto das Senectudes Tremulinas que indagam

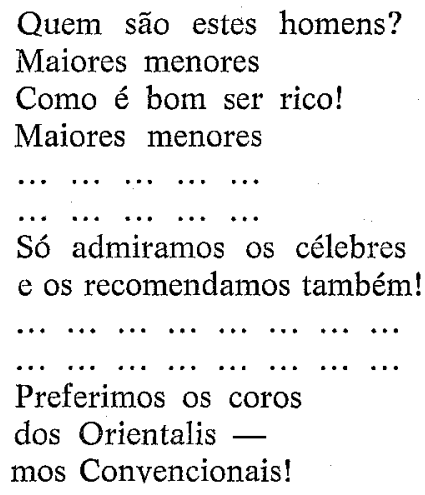

Só depois desse minueto, ouve-se, num recitativo, em tom de balada, a voz de Minha Loucura — que oscila, sem lugar fixo, no meio das juvenis comparsas -usando o diapasão retórico com que afinou, nos escritos sobre os Mestres do Passado, o elogio aos moços:

Dramas da luz do luar no segredo das frestas perquirindo as escuridões...

$\ldots \ldots \ldots \ldots \ldots \ldots \ldots$

Os cérebros das cascatas marulhantes

e o benefício das manhãs serenas do Brasil!

As Juvenilidades precipitam seu ardor num ritmo de inspiração profética, do qual subsistirá apenas, já quase ao final, o clamor transformado num estribilho
A passiflora! 17 o espanto! a loucura! o desejo!
Cravos! mais cravos para nossa cruz!

Replicam-1hes os Orientalismos Convencionais num tutti que se transforma em «solene marcha fúnebre»:

Para que cravos? Para que cruzes?

Submetei-vos à metrificação!
Para que as artes vivam e revivam use-se o regime do quartel!

${ }^{17}$ Gênero de planta a que pertenece o maracujá. 
Diante da repetida vociferação das juvenís cantores, o contracanto dos Orientalismos decai numa litania, obcessiva exaltação de sua própria importância, em que as mesmas palàvras

\section{$\ldots$ e as perpetuidades}

das celebridades das nossas vaidades;

das antiguidades às atualidades,

atropelam-se rimadas, até que as Juvenilidades lançam um repto insultuoso a ser preenchido, ad libitum, pelos executantes ou pelo leitor:

Seus

(A maior palavra feia que a leitor conhecer.)

À retirada dos oponentes, que fogem tapando os ouvidos, cala-se a osquestra, enquanto as Juvenilidades caem no solo a chorar "o arrependimento do tresvario final». Volta, então Minha Loucura, para o solo de encerramento, suave cantiga de ninar, após o que se entregará ao sono juntamente com os atletas do modernismo, ao mesmo tempo que «cresce uma enorme vaia de assobios, zurros, patadas». Nesse solo de encerramento reaparecem as borboletas invocadas no Coral de os Mestres do Passado, simbolizando, também aqui, a leveza, o vôo dos rebeldes acima dos insultos:

Diuturnamente cantareis e tombareis.

As rosas... As borboletas... Os orvalhos...

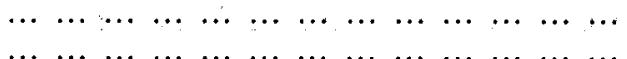

Venham os descansos veludosos

vestir os vossos membros... Descansai!

A representação da Semana de Arte Moderna como confronto estético entre passadistas e modernistas é apenas o primeiro plano de As Enfibraturas do Ipiranga. O plano de fundo, onde o sentido da composição se projeta, para além de seu significado mais óbvio, passa pela posição dramática das massas corais, representativas, dentro do espaço cênico, de grupos socialmente definidos, cada um dos quais correspondendo a certo modo de atuação, de pensamento e de sensibilidade. $O$ confronto artístico 
transfigura-se num estarrecido confronto social. Desdobram-se as fibras estéticas do modernismo em filamentos, em fibraturas ideológicas ${ }^{18}$.

Passadistas, os Orientalismos Convencionais são aliados dos conservadores da ordem, as Senectudes Tremulinas —milionários e burgueses, de que certamente se excluem os membros da «aristocracia» paulista, patrocinadores dos artistas e poetas que promoveram a Semana. A posição dos modernistas, as Juvenilidades Auriverdes, em baixo, nos parques do Anhangabaú, é a que deveriam ocupar os Sandapilarios Indiferentes, colocados, no entanto, no Viaduto do Chá. Dir-se-ia que os artistas rebeldes usurpavam o lugar real que aqueles últimos detinham, como força de trabalho, na sociedade paulista. O tratamento pejorativo dos operários - remoedores de tolices, enquanto Sandapilários- revela-nos o carater aristocrático, a "gratuidade antipopuplar» do movimento de 1922 quando nasceu, conforme reconheceria o autor de As Enfibraturas ao fazer, em 1942, o retrospecto histórico da Semana ${ }^{19}$. Somente no fim da década, por volta de 1930, conquistaram os participantes da Semana a consciência social das bases de nossa cultura, que os levaria a uma aproximação com o povo, no sentido de entidade política.

Mário de Andrade realizaria essa aproximação, afeiçoando, já fora da cena teatral da Semana de Arte Moderna, a tendência nacionalista dominante do modernismo a uma perspectiva crítico-satírica, isenta do tom alegórico-patriótico que marcava a linguagem dos rebeldes auriverdes. Secundando-os sem com eles confundir-se, a solista Minha Loucura também ficaria à margem do «nacionalismo embrabecido», por vezes exaltatório e patrioteiro, das Juvenilidades modernistas. Outro nome para Arlequim, foi ainda a Loucura-solista que inspirou a Mário uma experiência diferente da realidade nacional, antropológica e socialmente sopesada. Era o nacionalismo de conhecimento, que repontou, amorosamente, pouco mais tarde, nos versos de o Clã do Jaboti (1926):

Brasil amado não porque seja minha patria, Patria é acaso de migrações e do pão-nosso onde Deus der...

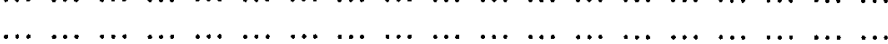

Brasil que eu sou porque é a minha expressão muito engraçada,

\footnotetext{
${ }^{18}$ Enfibratura: constituição por fibras, filamentosa.

19 «Pelo seu carater de jogo arriscado, pelo seu espírito aventureiro ao extremo, pelo seu internacionalismo modernista, pelo seu nacionalismo embrabecido, pela sua gratuidade antipopular, pelo seu dogmatismo prepotente, era uma aristocracia do espírito» (Mário de Andrade, «O Movimento Modernista», em Aspectos da Literatura Brasileria, cit., p. 236.
} 
Porque é o meu sentimento pachorrento,

Porque é o meu jeito de ganhar dinneiro, de comer e de dormir

( $\mathrm{O}$ Poeta come Amendoim»)

No conjunto da obra de Mário de Andrade, o verdadeiro epílogo do oratório profano, As Enfibraturas do Ipiranga, ocorreria em 1928, quando o Arlequim de Paulicéia Desvairada ressurge sob a figura do «heroi sem nenhum carater», que deu nome a Macunaima - polifonia de lendas e mitos, em que as fibras estéticas do modernismo se desvencilham de seus filamentos ideológicos, consumidos numa visão crítico-satírica da sociedade e da cultura brasileiras, ao mesmo tempo canto coral dos contrastes e perplexidades do nosso povo.

Julho, 1982. 
